\title{
Penanggulangan Kemiskinan di Indonesia * Catatan Program IDT dan Kemiskinan Kota
}

\author{
Oleh : Edy Suandi Hamid
}

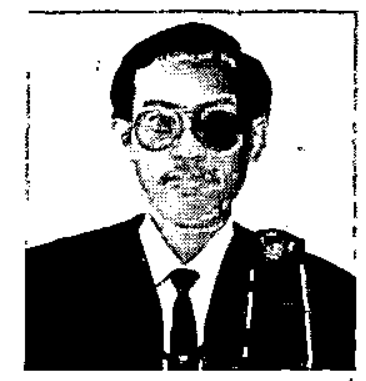

Edy Suandl Hamid, adalah dosen negeri yang dipekerjakan pada Fakultas Ekonomi Universitas Islam Indonesia, disamping juga sebagai staf peneliti pada Pusat Penelitian Pembangunan Pedesaan dan Kàwasan (P3PK). UGM dan Sekretaris Ikatan Sarjana Ekonomi Indonesia DIY. Lahir di Tanjung Enim, 11 Desember 1957, dan menyelesaikan studi pembangunan (Umum), april 1983 S1 serta S2 dari Faculty of Economic. Thammasat University, Bangkok 1990.

Pernah menjadi wartawan dan redaksi ekonomi harian Kedaulatan Rakyat, serta Pimpinan Redaksi Majalah Equilibrium (FE UGM): Kini aktif dalam kegiatan penelitian yang menyangkut masalah pedesaan. Menulis buku Pengantar Teori Perilaku Konsumen (bersama Drs. Effendy Ari, 1985), menyunting buku Kredit Pedesaan dilndonesia (bersama Prof. Mubyarto, 1986) dan Meningkatkan Efisiensi Nasional (bersama Prof. Mubyarto, 1987). Saat ini menjabat sebagai Pjs. Dékan FE UII,

Jika kita cermati dari berbagai isuisu pembangunan ekonomi yang sangat menonjol dan masih terus "laku" menjadi komoditi yang banyak diminati media massa di tanah air sejak dibentuknya Kaainet Pembangunan VI sekarang ini, maka pilihan tampaknya akan jatuh pada masalah kemiskinan. Memang ada juga isu-isu lain yang menonjol seperti berkaitan dengansoal regionalisasi ekonomi(AFTA), deregulasi-deregulasi ekonomi; SDSB, GSP(Generalized System of Preferences), inflasi yang tinggi, utang luar negeri yang kian menggelembung, merosotnya harga ekspor minyak, perpajakan, sampai soal kredit macet. Namun demikian berbagai isu yang disebut belakangan tersebut publikasinya bersifat temporer dan timbultenggelam, sementara isu kemiskinan masih terus bertahan dan seakan menjadi "trade mark" program kerja KabinetPembangunan VI.

Banyaknya pembicaraan tentang kemiskinan ini memang tidak bisa dilepaskan dari tekad pemerintah yang ingin secepatnya menghapuskan kemiskinan absolut yang jumlahnya masih cukup besar di tanah air. Dan tekad itu ditunjukkan lewat suatu paket program melalui Inpres Desa Tertinggal (IDT), àtau yang sebelumnya semasa masih konsep -dipublikasikan dengan istilah Inpres Desa Miskin (IDM). Untuk penanganan pengentasan kemiskinan ini, sebelumnya sudahditunjukpulaseorang Asisten Menteri Negara Perencanaan Pembangunan (PPN)/ Ketua Bappenas khusus untuk bidang peningkatan pemérataan dan 
penanggulangan kemiskinan, yang dipercayakan kepada Prof.Dr. Mubyarto. Dipegangnya jabatan Asmen ini pada Prof. Mubyarto merupakan faktor pendorong pula yang kian mempopulerkan isu kemiskinan tersebut, karena nama tersebut merupakan public figure yang sebelumnya sangat vokal dalam membahas (dan mengkritik) kebijakan pemerintah dalam soal penanggulangan kemiskinan dan pemerataan.

Terlepas dari semua itu, yang pasti secara absolut maupun relatif -- dilihat dari porsi jumlah orang miskin terhadap jumlah penduduk secara keseluruhan -- sudah semakin menurun. Pada tahun 1970 (awal Pelita 1) jumlah penduduk miskin masih mencapai 70 juta orang (60 persen dari jumlah penduduk) menjadi 54,2 juta $(40,08 \%)$ tahun 1976 , dan tinggal 27,2 juta $(15,08 \%)$ tahun 1990 . Angka terakhir, dengan batas kemiskinan yang bisa diperbandingkan, jumlah penduduk miskin ini tinggal 25,9 juta atau $13,67 \%$ pada tahun 1993 (lihat tabel 1)
Angka-angka ini bagaimanapun telah menunjukkan 'adanya prestasi pembangunan selama pembangunan jangka panjang tahap pertama (PJP I), yang juga mendapat banyak pujian dari pihak-pihak yang selama ini banyak membantu pembangunan Indonesia, seperti Bank Dunia, Bank Pembangunan Asia, ạtaupun negara donor lainnya. Untuk menghitung jumlah penduduk miskin ini, batas yang digunakan pemerintah (c/q Biro Pusat Statiștik) sejak 1976 adalah berdasarkan kecukupan pangan 2100 kalori per kapita perhari, yang kemudian dirupiahkan sesuai dengan harga berlaku. Jadi, secara statistik angka-angka tersebut, sepeni tertera pada Tabel 1, memang bisa diperbandingkan karena menunjukkan angkra riil. Dengan kata lain, harus diakui telah banyak penduduk yang berhasil diangkatt tingkat kesejahteraannya sclama PJP I terscbul.

Walaupun jumlah penduduk yang hidup di bawah garis kemiskinan kian mengecil, namun másih juga sering timbul pertanyaan mengenai garis batas, TABEL 1.

BATAS, PERSENTASE DAN JUMLAH PENDUDUK MISKIN 1976-1993

\begin{tabular}{|c|c|c|c|c|c|c|c|c|}
\hline \multirow{2}{*}{ TAHUN } & \multicolumn{2}{|c|}{$\begin{array}{l}\text { BATAS MISKIN } \\
\text { (Rp./Kapita/bulan) }\end{array}$} & \multicolumn{3}{|c|}{$\begin{array}{l}\text { PERSENTASE PENDUDUK } \\
\text { MISKIN }\end{array}$} & \multicolumn{3}{|c|}{$\begin{array}{l}\text { JUM!LAH PENDUDUK } \\
\text { MISKIN }\end{array}$} \\
\hline & KorA & PEDESANN & KOTA & PEDESAUN & KOTA+DESA & KOTA & PEDESAMN & KOTA+DESA \\
\hline 1976 & 4522 & 2849 & 38,79 & 40,37 & 40,08 & 10,0 & 44,2 & 54,2 \\
\hline 1978 & 4969 & 2981 & 30,84 & 33,38 & 33,31 & 8,3 & 38,9 & 47,2 \\
\hline 1980 & 6831 & 4449 & 29,04 & 28,42 & 28,56 & 9,5 & 32,8 & 42,3 \\
\hline 1981 & 9777 & S 877 & 28,06 & 26,49 & 26,85 & 9,3 & 31,3 & 40,6 \\
\hline 1984 & 13731 & 7746 & $23,14^{\prime}$ & 21,18 & 21,64 & 9,3 & 25,7 & 35,0 \\
\hline 1987. & 17381 & 10294 & 20,14 & 16.44 & 17,42 & 9.7 & 20,3 & 30,0 \\
\hline 1990 & 20614 & 13295 & $\cdot 16,75$ & 14,33 & 15,08 & 9,4 & 17,8 & 27,2 \\
\hline 1993 & 27905 & 18244 & 13,45 & 13,79 & 13,67 & $8,7^{\circ}$ & 17,2 & 25,9 \\
\hline
\end{tabular}


kemiskinan yang ditetapkan apakah memang sudah layak atau belum bagi pemenuhan kebutuhan dasar manusia. Jika hal ini dipertanyakan memang bisa saja angka-angkanya mengalami perubahan. Bahkan jika batas kemiskinan itu, baik di 'desa maupun di kota dinaikkan dengan Rp. 1.000 - Rp. 2.000 saja. bisa jadi jumlah penduduk miskin tersebut bertambah puluhan juta jiwa. Atau jika dilihat .dari pemenuhan kebutuhandasarmanusia, yakni mencakup kecukupan minimal akan kebutuhan dasarmanusia. yakni mencakup kecukupan minimal akan kebutuhan pangan, sandang, pemukiman, pendidikan dan kesehatan, maka dapat dipastikan batas kemiskinan yang digariskan BPS itu terlalu rendah, dan berarti jumlah penduduk miskin yang sebenamya masih jauh dari angka yang dipublikasikan itu. Namun demikian ini tidak menghilangkan kesimpulan kïla bahwa selama PJP I tersebut jumlah penduduk yang sangat melarat sudah banyak yang berhasil diangkat ke ting'kat pendapatan yang lebih tinggi, dan berhasil mengkonsumsi barang dan jasa lebih banyak dibandingkan dengan sebelumnya.

\section{Inpres Desa Tertinggal}

Sebagaimana di singgung di muka, untukmengatasi kemiskinan ini pemerintah kini mencoba menanggulanginya mclalui Inpres Desa Tertinggal (IDT). Ini tidak berarti bahwa sebelumnya tidak ada program maupun proyek untuk menanggulangi kemiskinan ini. Proyek ataupun prograin tersebut bahkan sudah sangat banyak, baik dilaksanakan pemerintah maupun nonpemerintah. Hanya sajabanyak prógram demikian, khususnya di pedesaan, tidak terkoordinasi satu dengan lainnya atau berjalan sendiri-sendiri sehingga hasilnya tidak optimal.

Dári kesimpulan seminar "Peningkatan Kesejahteraan Umat Melalui Pemberantasan Kemiskinan" (18-20/6/ 1993) mènyuratkan tentang keadaan tersebut. Dikemukakan, banyak kegiatan dari departemen tertentu tidak dikoordinasikandenganpemerintah daerah. Aparat departemen yang berada di daerah (Kanwil) lebih bertanggung jawab pada departemen teknisnya di Pusat. Akibat dari sikap itu, bukan saja program/proyek pemerintah menjadi tumpang tindih, namun lebih dari itu banyak kegiatan di daerah/ desa untuk mengentaskan kemiskinan ini tidak diketahui pemerintah daerah.

Adanya kenyataan yang demikian membuat berbagai program penanggulangan kemiskinan yang dilakukan oleh berbagai pihak tersebut terkesan berjalan sendiri-sendiri. Kegiatan yang ada menjadi tumpang tindih dan tidak jarang terjadi semacam persaingan guna mensukseskan kegiatan yang ditangani masing-masing pihak. Bantuan kredit ataupun prasarana produksi pada masyarakat miskin, misalnya, banyak diterima masyarakat pedesaan. Masyarakat yang menerima bantuan itu ada yang menginterpretasikan bahwa'itu adalah pemberian cuma-cuma yang lidak perlu dikembalikan, schingga tidak merasa perlu sccara oplimal memanfaatkannya secara produktil: Dengan demikian bantuan menjadi scmacam proyek karitatil yang sukar diharapkan berkembang efisien dan berdampak ekonomis untuk mentikkan pendapatan massyarakat miskin secara signifikan. Alau, kalaupunpemberian kredit itu benar-benar ditagih, masyarakat kesulitan mengangsur atau membayar karena terlalu banyak pinjaman pada pihak 
yang menawarkan kredit tersicbul.

Dalam IDT tampaknya koordinasi kegiatan sangat terkait dengan birokrasi desa, khususnya dalam kaitan dengan penilaian dan perselujuan rencanil kegiatan. Bahkan program tersebul juga diinformasikan untuk memperoleh dukungan program-program scktoral: Berbeda dengan kebijakan-kcbijakan terdahulu, maka penyaluran IDT ini akan berlangsung menyentuh penduduk miskin di daerah yang masuk daliam kategori "desa miskin" dan kemungkinan mclibatkan lembaga swadaya. masyarakat sebagai pendamping. Pendamping ini bertugas menyertai proses pembentukan dan penyelenggaraan kelompok masyarakat yang akan memperolch bantuan sebagai fasilitator, komunikalor dan dinamisator. Dengan pola seperti ini diharapkan dana IDT bisa betul-betul efektif mencapai sasarannya.

Secara konsepsional dirumuskan bahwa program IDT dimaksudkan untuk menumbuhkan dan memperkuat kemampuan penduduk miskin untuk meningkatkan taraf hidupnya dengan membuka kesempatan berusaha.,Untukitu, program IDT diarahkan pada pengembangan kegiatan sosial-ekonomi untukmewujudkankemandirian penduduk miskin di desa-desa miskin dengan menerapkan prinisp-prinsip keswadayaan dan partisipasi. Kegiatan sosial-ekonomi yang dikembangkan adalah kegiatan produksi dan pemasaran, terutama yang sumberdayanya tersedia di lingkungan masyarakat setempat (lihat Program Panduan. Inpres Desa Tertinggal, Bappenas-Depdagri, 1993):

Melihat sasaran yang demikian maka dapat dikatakan bahwa dengan IDT diharapkan kelomok miskin ini menjadi pelaku-pelaku ekonomi yang mampu memperjual-belikan produksi barang/jasa yang dihasilkannya. Untuk itu pemerintah memberikan bantuan dana serta pembinaan kegiatan yang dipilih benar-benar tepat dan juga dapat dioperasionalkan. Dengan pola pemberikan dana yang disertai bimbingan; serta penyaluran yang bertahap sesuai kebutuhan, maka cara ini bisa diharapkan cukup efektif. Persoalannya adakah pendamping -- yang bisa melibatkan perguruan tinggi, LSM, Ormas dan Tenagatenaga Pelatih -- yang betul-betul mau dan mampu secara intens untuk melakukan peran pembimbing produksi, manajeman. pemasaran, dan sebagainya.

Jika IDT ingin menciptakan semacam enterprenur-enterprenur kecil makakonsep pendamping dan pembimbing yang jelas sangat diperlukan oleh pihak yang akan berfungsi sebagai pendamping tersebut. Dengan demikian mereka mempunyai pengetahuan dan pemahaman yang jelas akan tugasnya. Belakangan ini timbul ide untuk memperbantukan pada desa-desa tertinggal para tenaga sarjana. Ide ini memang sangat baik. Namun apakah para tenaga sarjana itu, yang dapat diduga adalah para tenaga sarjana yang baru atau yaing sulit mendapat (atau menciptakan) pekerjaan, mampu menggerakkan dan mengembangkan intuisi usaha para penduduk miskin di pedesaan ?. Ini merupakan pertanyaan yang skeptik. Namun demikian jika ada acuan yang jelas dan pelatihan sebelumnya bagi para tenaga pendamping, maka berbagai kekhawatiran itu mungkin bisa dikurangi.

\section{Peran LSM}

Yang cukup menarik dari rencana 
pelaksanaan teknis dari IDM ini adalah àkan dilibatkannya LSM-LSM yang ada secara langsung dalam program IDT tersebut. Jika kita membayangkan LSMLSM tersebut seperti Dian Desa. Bina Swadaya, LP3ES, Yayasan Indonesia Sejahtera darisejenisnya.maka kita optimis bahwa target untuk secara lcbih cepat menghapuskan kemiskinan ini bisa diwujudkan. LSM-LSM scmacain ini sudah mempunyai pengetahuan dan pengalaman yang luas tentang pengatan kemiskinan di pedesaan. Mereka sejak awal berkecimpung langsung dengan proyek-proyck pengentasan kemiskinan dan pengembangan swadaya masyarakal.

Namun demikian LSM yang seperti itu jumlahnya sangat terbatas. Yang banyak adalahLSM-LSM kecil yang secara teknispraktis pengetahuannya perlu lebih ditingkatkan. Aparat mereka juga jauhlebih sedikit dibandingkan dengan aparat birokrasi yang ada (atau sampai) di desadesa, yang selama ini sudah melaksanakan berbagai proyek yang arahnya untuk membantu si miskin. Oleh karena itu untuk mendukung perwujudan sasaran dari IDT tersebut, maka bukan saja masih memerlukan dukungan birokrasi dcsa atau kelurahan, mclainkan juga pembekalan pada LSM-LSM kecil, tcrmasuk lembaga seperti Karang Taruna, kelompokkelompok pengajian (oleh LSM yang besar) agarkegiatannya terarah pada sasaran yang sama.

Soal dukungan birokrasi desa tidak berarti dukungan dalam bentuk tisik dari aparat desa yang ada. Yang penting adalah dukungan politis dan moral, schingga memudahkan LSM-LSM ini menggerakkan partisipasi masyarakat desa untuk mewujudkan sasaran IDT tersebut. Ini penting karenaselama ini tidak semua desa/ wilayah mendukung kehadiran LSM.

Pengalaman sebuahLSMbesaryang ingin menyalurkan kredit bagi si miskin pernah mendapat "hambatan" dari pemerintah desa, yang "menyarankan" untuk menyalurkan kredit tersebut lewat desa saja. Tujuannya, agar pengembálian kredit tersebut "lebih aman". Penolakan LSM atas saran tersebut ditanggapi oleh aparat desa itu dengan pemyataan untuk "tidak bertanggung jawab kalau kredit itu tidak kembali".

Hal seperti ini menyiratkan bahwa desa tersebut tidak memberikan dukungan politis atas proyek yang sebetulnya ditujukan untuk membantu masyarakat di wilayahnya, dan tentu saja jika awal kegiatan sudah seperti ini akan membuat "kagok" LSM tersebut. Untuk menghindarkan hal seperti ini, maka yang perlu disosialisasikan sekarang adalah bagaimana agar para birokrasi desa dapat memandang LSM-LSM itu sebagai mitra kerja sama dan bukan sebagai kompctitor.

Namun demikian pemerintah juga perlu mewaspadai LSM-LSM yang diharapkanmembantu program pemerintah ini. Yang pertama. agar dihindari munculnya LSM-LSM yang sckedar menangkap "pcluang bisnis" dári IDT ini. Karena bagaimanapun proyck ini menyangkut dana yang sangat besar, sehingga sangat mungkin ada pihak atau kelompok tertentu untuk memanliatkan kescmpatan yang ada unluk kepentingankepentingan pribadi.

Kedua, dalam pelaksanaan IDT ini makaLSM-LSM yang alda perlu diingalkan agar benar-benar lepas dari kepentingan kelompok atau misi latin yang dibawanya. Sebagaimana diketahui, scbagian LSM 
berafiliasi atau membawa "bendera". untuk umat tertentu. Proyck ini menjadli tidak akan berhasil kalau dalam menyalurkan IDT ini LSM tersebut tetap membawa bendera tersebut, sehingga memberikan perlakuan yang diskriminatif.

\section{Kemiskinan Kota}

Dengan secara tegas program ini ditujukan pada kelompok miskin, maka dibandingkan berbagai program scjenis yang banyak diintrodusir di pedesaan, kebijakan ini memang lebih bisad dihalapkan mengatasi problcma kemiskinan yang ada, khususnya yang berkailan dengan jumlahnya yang secara absolut massih sangat besar. Namun demikian, dalam menjawab persoalán kemiskinan ini perlu juga dilihat fakta tentang kemiskinan itu sendiri yang tidak selalu berada pada desa miskin atau pada desa-desa terbelakang.

Masyarakat miskin yang ada di tanah air pada kenyataannya banyak di daerah perkotaan. Bahkan secara absolut proses penurunannya berjalan sangat lamban. Di pedesaan, misalnya, jumlah penduduk miskin pada tahun 1976 mencapai 44,2 juta jiwa, dan kemudian menurun menjadi tinggal 17,2 jutajiwa tahun 1993. Sementara itu di perkotaannya penurunannya relatif tidak berarti, yakni dari 10 juta (1976) menjadi 8,7.juta (1993), sebagaimana yang ditunjukkan dalam tabel $\mathrm{l}$.

Dari study yang dilakukan di P. Jawa Dr. William L. Collier juga menyimpuikan bahwa kemiskinan yang gawat justru berada di sekitar perkotaan (Kompas, 5/8/93). Adanya arus urbanisasi telah pula menambah kekumuhan bagian wilayah perkotaan yang menunjukkan. citra kemiskinan itu.

Fakta dan kajian di atas menunjukkan bahwa perhatian pada penduduk miskin di perkotaan tidak bisa diangkal dari kemiskinannya, sangat mungkin pula muncul proses pemiskinan baru sebagai akibat dari arus urbanisasi yang tidak mendapalkan penanganan secara memadai di wilayah perkotaan. Masalah ini agaknya akan mendapat perhatian pula dari pemerintah, karena -- menurut yang saya dengar -- walaupun namanya Inpres Desa Miskin, danaproyek ini juga akan mengucur di daerah kelurahan di perkotaan. Namun yang ingin diingatkan di sini adalah agar perhatian kita (di luar IDT) tidak "melupakan" masalah fenomena kemiskinan di perkotaan tersebut.

Yang juga perlu dicenmati adalah pendudak miskin yang berada di pedesaan namin berada di luar desa miskin. Scbagaimana diketahui, penducluk miskin sebanyak 27,2 juta jiwa itu lidaklah seluruhnya berada pada kantong-kaniong yang sama. Namun demikian; ada di antaranya hidup di luar desa miskin alau di luar kantong kemiskinan:

Program Inpres Desa Teringgal tampaknya tidak akan menyentuh masyarakat miskin yang berada di luar IDT ini. Pertanyaan yang timbul tenlunya adalah program atau proyek apa yang akan mengentaskan kemiskinan penduduk di luar desa atau kelurahan yang terbelakang tersebut? Ataukah masih terdapat pemikiran yang percaya pada teori trickle down cffecl, sehingga beranggapan bahwa pada daerah dan masyarakat yang sudah "kaya" akan menarik masyarakat lainnya juga untuk tidakmiskin? Untukpertanyaan yang kcdua ini, saya yakin tidak. Karena konseptor di balik IDT bukanlah orang yang seluju dengan teori tersebut.

Namun demikian yang pasti bagi si 
miskin di luar desa miskin atau tertinggal ini masih belum ada program ekstra untuk mengentaskan kemiskinannya. Artinya, proyek-proyek yang sudah ada selama ini masih diharapkan bisa membantu meningkatkan kemampuan ekonominya. Ini memang "kelemahan" dari IDT, karena berfokus pada lokasi dan bukan pada orangnya. Jadi berbeda kalau namanya bukan Inpres Desa Tertinggal tetapi "Inpres Orang Tertinggal". Namun demikian hal ini bisa dipahami kalau kita berbicara soal prioritas, karena secara teknis dan praktis proyek IDM ini relatif lebih mudah dilaksanakan dibandingkan kalau harus diarahkan langsung pada setiap orang miskin yang tersebar di tanah air.

\section{Daftar Pustaka}

Edy Suandy Hamid, "Inpres Desa Tertinggal dan Kendalanya", dalam Wawasan, Semarang, 4 September 1993.

Mubyárto dkk, Desa Tertinggal, Aditya Media, Yogyakarta, 1993.

Mubyarto, "Dari Program Stabilisasi sampai Kebijaksanaan Pembangunan Berkelanjutan", makalah dalam Seminar Analisis Antar era Pembangunan Indonesia, FEUII-ICMI, Yogyakarta, 1994.

MUI, P3PK UGM dan Universitas Mercu Buana, "Peningkatan Kesejahteraan Umat Melalui Pemberantasan Kemiskinan", Prosiding Seminar, Jakarta, 1993. 